\title{
High incidence of urinary tract infection in patients with coeliac disease
}

\author{
Robert Saalman, Sven-Petter Fällström
}

\begin{abstract}
The concomitant occurrence of urinary tract infection (UTI) and coeliac disease was studied retrospectively among children with coeliac disease. There was a significantly higher risk of first time UTI in children with coeliac disease than in an unselected population of children. In the majority of cases UTI was associated with untreated, active coeliac disease.

(Arch Dis Child 1996; 74: 170-171)
\end{abstract}

Keywords: urinary tract infection, coeliac disease.

During recent years we have repeatedly observed concomitant urinary tract infection (UTI) and coeliac disease in young children. The incidence of first time UTI was therefore studied retrospectively among all children with coeliac disease diagnosed in our department during a period of 10 years and compared with that in an unselected population.

\section{Methods}

Between 1982 and the end of 1991, 107 patients with coeliac disease were diagnosed at the Department of Paediatrics, Mölndal Hospital. The median age of the patients -80 girls and 27 boys - was 15 months (range 8 months to 18 years) at the time of the primary small intestinal biopsy. Coeliac disease was diagnosed according to the criteria of European Society for Paediatric Gastroenterology and Nutrition (ESPGAN). ${ }^{1}$ The diagnosis of UTI was based on generally accepted criteria of bacteriuria ${ }^{2}{ }^{3}$ as follows: 1000 bacteria/ml urine in samples obtained by suprapubic aspiration, or $100000 \mathrm{bacteria} / \mathrm{ml}$ of identical strains in two separate voided specimens, or 100000 bacteria $/ \mathrm{ml}$ in urine obtained by one midstream urine sample along with a positive nitrite test. The cumulative incidence of UTI at the age of 72 months in the group of coeliac children was compared with that calculated from a study of first time UTI in an unselected population from this region. ${ }^{4}$ The same UTI criteria were used in both groups. Urine samples from the two groups were sent to the department of clinical bacteriology, University of Göteborg, where they were analysed by the same staff and with identical techniques for quantitative urine cultures and identification of bacterial species.

As the occurrence of UTI varies with age, the children were divided into age groups of 12 months. The size of the unselected population at risk in each age interval of 12 months was virtually constant and consisted of approximately 3500 boys and girls respectively. For statistical analysis the most powerful unbiased test, within each age interval, for comparison of two Poisson distributions (Lehmann) was applied. ${ }^{5}$ The results were pooled to one test adding the test variables of each interval. Two sided tests were used.

\section{Results}

A first time UTI was found in 18 out of the 107 patients with coeliac disease, 13 girls and five boys, with a median age of 12 months (range 4 to 66 months) at the time of the diagnosis of UTI. The cumulative incidence of first time UTI in the group of children with coeliac disease was $16.3 \%$ for girls and $18.5 \%$ for boys. In comparison, the calculated cumulative incidence of first time UTI at the age of 72 months in an unselected population of children was found to be $7 \cdot 1 \%$ for girls and $3.2 \%$ for boys. Twenty five out of 107 children with coeliac disease had not yet reached the age of 72 months, which may lead to an underestimation of the cumulative incidence of UTI for this group. Thus a significantly higher risk of first time UTI was found in young children with coeliac disease - both for girls $(p=0.006)$ and for boys $(p=0.02)$ - than that found in the unselected population of children. The estimated risk ratios for first time UTI (coeliac children versus reference population) were $2 \cdot 7$, confidence interval $1 \cdot 3$ to $4 \cdot 0$, for girls,

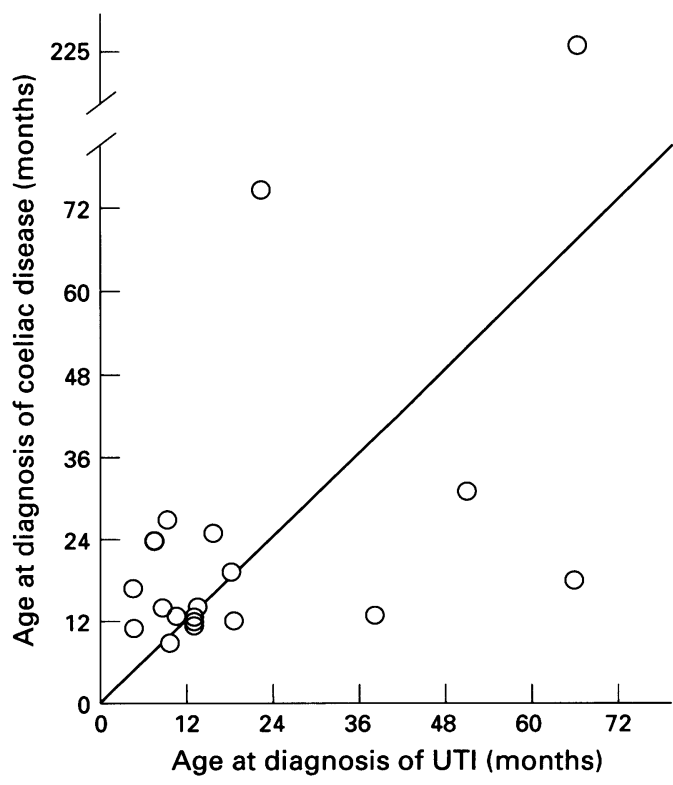

Figure 1 Relation between the time of diagnosis of coeliac disease and the time of diagnosis of UTI. Points above the diagonal line indicate UTI diagnosis before coeliac disease diagnosis and points below the line indicate coeliac diagnosis before UTI diagnosis. 


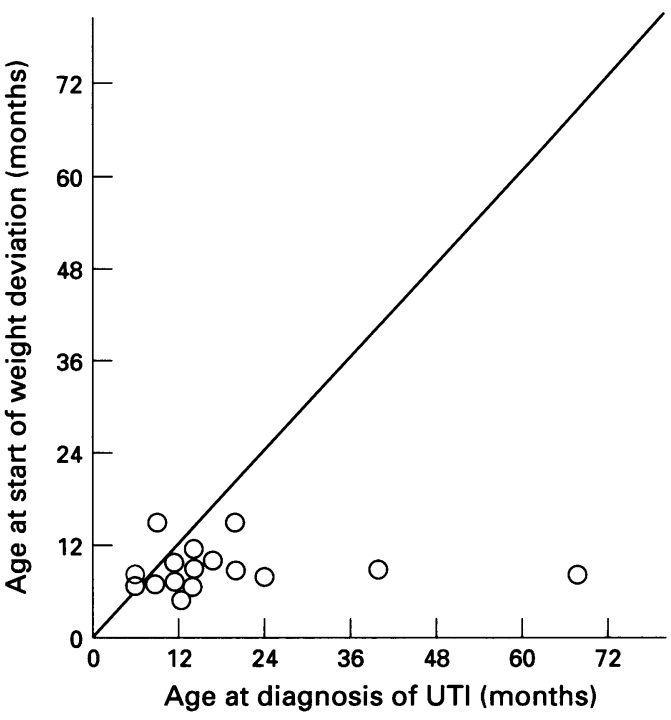

Figure 2 Relation between the time of onset of weight deviation and the time of diagnosis of UTI in the 16 out of 18 cases showing weight deviation. Points above the diagonal line indicate UTI diagnosis before weight deviation and points below the line indicate weight deviation before UTI diagnosis.

and $4 \cdot 5$, confidence interval $1 \cdot 2$ to $9 \cdot 6$, for boys.

All positive urine cultures showed 100000 bacteria/ml. Most of the children (15/18) were infected with $E$ coli bacteria. Equal numbers of febrile and non-febrile UTIs were seen. Radiological investigations were performed in 15 cases. Abnormalities were found in five patients: unilateral grade 3 reflux and $40 \mathrm{ml}$ residual urine, grade 3 bilateral reflux, unilateral grade 2 reflux, diverticulum of the bladder, focal renal scarring with loss of parenchyma, and trabeculated bladder with 38 $\mathrm{ml}$ residual urine. This rate of abnormality does not differ significantly from that reported in children with first time UTI. ${ }^{6}$

The majority of the coeliac children with UTI -14 out of 18 - were on a gluten containing diet at the time of the UTI diagnosis (before primary intestinal biopsy $n=12$; on gluten challenge $n=2)$. A large proportion of the children developed symptoms of UTI during the period immediately before the diagnosis of coeliac disease (fig 1). However, in most cases the onset of weight deviation, probably indicating the initial phase of coeliac disease, preceded the first recorded symptoms of UTI (fig 2).

\section{Discussion}

We found an increased incidence of first time urinary tract infection in young children with coeliac disease compared with an unselected population. The high incidence of UTI in untreated coeliac disease could be explained as an effect of the coeliac symptoms drawing attention to the UTI. This would, however, imply a considerable underestimation of UTI in the unselected children in the area, which we think is unlikely. In Göteborg area a long standing interest in the clinical picture of UTI in children and unique opportunities for epidemiological studies have produced reliable data on the incidence and natural history of UTI. Repeated studies from this region have consistently shown a higher incidence of UTI in children than in other areas. ${ }^{48}$ Because of a high degree of awareness of UTI and its clinical picture in childhood, the good availability of medical care, and the frequent use of urine cultures in symptomatic young children, the number of undiagnosed cases of UTI is likely to be low. UTI in coeliac disease appears to be associated with untreated, active coeliac disease. Possible explanations for the increased incidence of UTI could be an associated disturbance of urinary tract motility, for example bladder dysfunction, changes in the bacterial flora in the gut predisposing to contamination of the urinary tract, or a decrease of the immunological defence against infections.

In conclusion, untreated coeliac disease in young children seems to predispose to UTI, and the coexistence of the two diseases needs to be considered.

We thank Staffan Mårild for the providing of supplementary details about the epidemiological study of UTI in an unselected population, Anders Odén for expert statistical guidance, and Ulf Dahlgren for his help in preparing the manuscript.

1 Walker-Smith J, Guandalini S, Schmitz J, Shmerling D, Visakorpi J. Revised criteria for diagnosis of coeliac disease. Visakorpi J. Revised criteria for diagnosis of coeliac disease. Report of Working Group of European Society of Paediatric Gastroe

2 Jodal U. The natural history of bacteriuria in childhood Infect Dis Clin North Am 1987; 1: 713-29.

3 Jodal U, Hansson S. Diagnosis of urinary tract infections. Curr Pediatr 1991; 1: 98-102.

4 Mårild S. Aspects of pathogenesis and renal development in child hood pyelonephritis. Göteborg: University of Göteborg 1989 [dissertation]

5 Lehmann EL. Testing statistical hypotheses. New York: John Wiley, 1959.

6 Hellström M, Jakobsson B, Mårild S, Jodal U. Voiding cystourethrography as a predictor of reflux nephropathy in cystourethrography as a predictor of reflux nephropathy in children with

7 Hellström A, Hanson E, Hansson S, Hjälmås $K$, Jodal U. Association between urinary symptoms at 7 years old and Association between urinary symptoms at 7 years old and previous

8 Winberg J, Andersen HJ, Bergström T, Jacobsson B, Larson $\mathrm{H}$, Lincoln $\mathrm{K}$. Epidemiology of symptomatic urinary tract infection in childhood. Acta Paediatr Scand Suppl 1974 1974: 1-20. 